\title{
Docosahexaenoic acid inhibits the invasion of MDA-MB-231 breast cancer cells through upregulation of cytokeratin-1
}

\author{
VINCENT BLANCKAERT ${ }^{1,2}$, VINCENT KERVIEL ${ }^{1,2}$, ALEXANDRA LÉPINAY $^{1,2}$, \\ VANESSA JOUBERT-DURIGNEUX ${ }^{3}$, HUBERT HONDERMARCK ${ }^{4}$ and BENOÎT CHÉNAIS ${ }^{1}$ \\ ${ }^{1}$ Mer, Molécules, Santé (EA2160), IUML-FR3473 CNRS, Université du Maine, F-72085 Le Mans; \\ ${ }^{2}$ IUT de Laval, Department of Bioengineering, BP 2045, F-53020 Laval Cedex 9; ${ }^{3}$ CERPEM, Laval Mayenne \\ Technopole, F-53001 Laval, France; ${ }^{4}$ School of Biomedical Sciences and Pharmacy, Hunter Medical Research \\ Institute, Faculty of Health and Medicine, University of Newcastle, Callaghan, NSW 2308, Australia
}

Received December 18, 2014; Accepted February 5, 2015

DOI: 10.3892/ijo.2015.2936

\begin{abstract}
Docosahexaenoic acid (DHA), the main member of the omega-3 essential fatty acid family, has been shown to reduce the invasion of the triple-negative breast cancer cell line MDA-MB-231, but the mechanism involved remains unclear. In the present study, a proteomic approach was used to define changes in protein expression induced by DHA. Proteins from crude membrane preparations of MDA-MB-231 cells treated with $100 \mu \mathrm{M}$ DHA were separated by two-dimensional electrophoresis (2-DE) and differentially expressed proteins were identified using MALDI-TOF mass spectrometry. The main changes observed were the upregulation of Keratin, type II cytoskeletal 1 (KRT1), catalase and lamin-A/C. Immunocytochemistry analyses confirmed the increase in KRT1 induced by DHA. Furthermore, in vitro invasion assays showed that siRNA against KRT1 was able to reverse the DHA-induced inhibition of breast cancer cell invasion. In conclusion, KRT1 is involved in the anti-invasive activity of DHA in breast cancer cells.
\end{abstract}

\section{Introduction}

Docosahexaenoic acid (DHA) is a 22:6n-3, long-chain polyunsaturated fatty acid (PUFA) present in fat fish, fish oils (1) and in marine microalgae (2). Among numerous beneficial effects, such as in cardiovascular (3) or metabolic syndromes (4), DHA may play a preventive role in cancer $(5,6)$. The mechanism by which DHA could prevent tumorigenesis or directly target cancer cells remains unclear (7). However, it has been

Correspondence to: Dr Vincent Blanckaert, IUT de Laval, Département Génie Biologique, 52 rue des Drs Calmette et Guérin, BP 2045, F-53020 Laval Cedex 9, France

E-mail: vincent.blanckaert@univ-lemans.fr

Key words: breast cancer, cytokeratin-1, docosahexaenoic acid, omega-3, tumor cell invasion shown that DHA not only acts as an anti-proliferative agent by lengthening the cell cycle between the G2/M transition (8), but also it is capable of inducing apoptosis and reducing the invasive potential of the triple-negative breast cancer cell line MDA-MB-231 with an optimal amount of $100 \mu \mathrm{M}$ (9). DHA can modify the metastatic phenotype of cancer cells, emphasizing the anti-cancer potential of the omega-3 (n-3) PUFAs $(10,11)$. This anti-cancer activity of DHA is promising and could partly result in a modification of the lipid contents of the plasma membrane and its fluidity (12).

Metastasis is a multifactorial process involving extracellular matrix remodeling, extra- and intravasation, and requiring the involvement of a variety of cell surface proteins. For example, the urokinase-type plasminogen activator (uPA) and metalloproteinases (MMPs) are involved in extracellular matrix disorganization leading to the release of angiogenic factors such as VEGF or FGF, allowing the sprouting of new blood vessels and ultimately extra- and intravasation (13-15). Several studies have shown that lipid rafts in the plasma membrane can play an important role in cancer cells when n-3 PUFAs were added, as it altered the cholesterol levels and consequently cell migration, invasion and angiogenesis $(16,17)$. The DHA-induced decrease in breast cancer cell invasion may also be due to inhibition of voltage-gated $\mathrm{Na}^{+}$channels $(18,19)$. These voltage-gated channels also called neonatal $\mathrm{Na}_{v} 1.5$ are inhibited in a dose-dependent manner by DHA and the use of specific blockers, like tetrodoxin, can reduce the migration of MDA-MB-231 at the same level to that observed with DHA (18). Thus, DHA-induced suppression of cellular migration may occur via downregulation of neonatal $\mathrm{Na}_{\mathrm{v}} 1.5$ mRNA and functional protein expression (18). The localization of voltage-gated $\mathrm{Na}^{+}$channel in lipid rafts (20) may be affected by n-3 PUFA (19).

In addition, DHA may change the biophysical properties of lipid rafts decreasing the content of cholesterol and the distribution of key proteins such as EGFR, Src, heterotrimeric G-protein subunits, or sphingomyelinase. Among these proteins, the Src kinase might play an important role by regulating the migration and invasion of the MDA-MB-231 cell line (21). Src was shown to play a role in cancer and invasive- 
ness $(21,22)$ and was also related to other molecules such as Keratin, type II cytoskeletal 1 (KRT1) via integrin $\beta 1$ (23) or the voltage-gated $\mathrm{Na}^{+}$channels where one of its subunits can also be considered as an integrin (24). Together, plasma membrane and related cytosolic molecules appear to play an important role in the DHA-induced inhibition of breast cancer cell invasion.

In this context, we have decided to analyze changes in the protein content of crude membrane preparations from breast cancer cells treated with DHA. Two-dimensional electrophoresis (2-DE) and MALDI-TOF mass spectrometry were used and several proteins were identified as upregulated by DHA. Increase in the level of KRT1 was the major change and interestingly functional in vitro assays have shown its involvement in mediating the anti-invasive effect of DHA.

\section{Material and methods}

Cell culture. The triple-negative breast cancer cell line MDAMB-231 was purchased from ATCC (Manassas, VA, USA) and routinely grown as monolayers at $37^{\circ} \mathrm{C}$, in a humidified atmosphere with $5 \% \mathrm{CO}_{2}$, in minimum essential medium (MEM) (Sigma-Aldrich, Saint-Quentin Fallavier, France) supplemented with $10 \%$ fetal calf serum (FCS) (Gibco; Invitrogen, Cergy Pontoise, France), $20 \mathrm{mM}$ Hepes, $2 \mathrm{mM}$ L-glutamine, $100 \mathrm{U} / \mathrm{ml}$ penicillin/streptomycin (Sigma-Aldrich).

Crude membrane protein extraction. MDA-MB-231 cells were grown in $\mathrm{T} 75 \mathrm{~cm}^{2}$ flasks until reaching subconfluency. A set of $7 \times 10^{8}$ cells were treated, or not, with $100 \mu \mathrm{M}$ DHA (Sigma-Aldrich Chimie S.a.r.l.) for 24 h. After treatment, cells were rinsed three times with $10 \mathrm{ml}$ MEM and twice with $20 \mathrm{mM}$ phosphate buffer $\mathrm{pH} 7.4$ containing $150 \mathrm{mM}$ $\mathrm{NaCl}$. Cells were then detached with $2 \mathrm{ml}$ of Versene (Sigma-Aldrich) and centrifuged at $200 \mathrm{x} \mathrm{g}$ for $10 \mathrm{~min}$ at $4^{\circ} \mathrm{C}$. The supernatant was discarded and the cell pellet stored at $-70^{\circ} \mathrm{C}$. The membrane preparations were carried out on ice and at $4^{\circ} \mathrm{C}$ according to Venkateswaran et al (25). Briefly, the cell pellets were defrosted and homogenized in $3 \mathrm{ml}$ buffer A composed with $20 \mathrm{mM}$ Hepes, $200 \mathrm{mM}$ sucrose and $5 \mathrm{mM}$ EDTA. The suspension was then transferred in a $7 \mathrm{ml}$ Dounce and cells were disrupted with 40 strikes of pestle. The homogenate was centrifuged at $1,000 \mathrm{x} \mathrm{g}$ for $20 \mathrm{~min}$ at $4^{\circ} \mathrm{C}$ in order to pellet the nuclei. The supernatant containing the membranes was transferred in a tube for centrifugation. Prior to this step, four volumes of buffer $\mathrm{B}$ composed of $20 \mathrm{mM}$ Hepes, $1 \mathrm{mM} \mathrm{CaCl}, 1 \mathrm{mM} \mathrm{MgCl}{ }_{2}$ (all from Sigma-Aldrich). and $100 \mathrm{mM} \mathrm{NaCl}$ were added to the supernatant to decrease buffer density and to allow the best ionic environment for membrane proteins. The mixture was centrifuged at $60,000 \mathrm{x}$ f for $90 \mathrm{~min}$ at $4^{\circ} \mathrm{C}$ in order to obtain crude membrane pellets. The supernatants were removed and the pellets suspended in $500 \mu \mathrm{l}$ buffer B and washed twice in the same conditions. Aliquots of the pellets were taken for a protein assay using Bradford's method (Bio-Rad, Marnes-la-Coquette, France) with BSA (Sigma-Aldrich) as standard. Aliquots of $100 \mu \mathrm{g}$ membrane proteins were stored in Eppendorf tubes and centrifuged at 20,000 $\mathrm{x}$ g for $60 \mathrm{~min}$ at $4^{\circ} \mathrm{C}$. The pellets were then solubilized with $50 \mu 1$ of a lysis buffer suitable for isoelectric focusing (IEF) (urea $7 \mathrm{M}$, thiourea $2 \mathrm{M}$, CHAPS $2 \%$, DTT $40 \mathrm{mM}$ and $0.4 \%$ ampholytes 3-10) (GE Healthcare Europe GmbH, Vélizy-Villacoublay, France) containing 1\% ASB-14 (Sigma-Aldrich), and stored at $-70^{\circ} \mathrm{C}$.

2-DE samples. A total of $100 \mu \mathrm{g}$ of membrane proteins prepared as described above were lysed with $50 \mu \mathrm{l}$ of lysis buffer as described above and processed for IEF by incubation for $1 \mathrm{~h}$ in $2 \mu \mathrm{l}$ of $200 \mathrm{mM}$ tributylphosphine (TBP) (Sigma-Aldrich) followed by incubation for $1.5 \mathrm{~h}$ with $5 \mu \mathrm{l}$ $200 \mathrm{mM}$ iodoacetamide (IAM) (GE Healthcare). At this stage, samples were loaded for IEF. Three independent experiments were carried out in duplicate.

$I E F$ and SDS-PAGE. IEF was performed using Ettan IPGphor 3 apparatus using $7 \mathrm{~cm}$ strips with pH 3.0-10.0 (both from GE Healthcare Europe $\mathrm{GmbH}$ ). Strips were rehydrated overnight at room temperature according to the manufacturer's instructions with DeStreak Rehydration Solution containing 0.4\% ampholytes $\mathrm{pH}$ 3.0-10.0 (GE Healthcare). The samples $(100 \mu \mathrm{g})$ were cup-loaded near the anode of the IPG strips and three drops of mineral oil were introduced in the cups. Then, the tray was filled with mineral oil. The run was defined as follows: step at $500 \mathrm{~V}$ for $500 \mathrm{Vh}$, gradient to reach $3,000 \mathrm{~V}$ for $5,000 \mathrm{Vh}$, step at 3,000 V for 12,000 Vh, step $1,000 \mathrm{~V}$ for $1,000 \mathrm{Vh}$. Once the IEF was completed, the strips were processed for SDS-PAGE after equilibration in urea $6 \mathrm{M}$, PlusOne Glycerol $30 \% \mathrm{w} / \mathrm{v}$, SDS $2 \% \mathrm{w} / \mathrm{v}$ (Bio-Rad), 0.125 M Tris, 0.1 M HCl containing $50 \mathrm{mM}$ DTT (first equilibration step; Sigma-Aldrich) and $150 \mathrm{mM}$ IAM (second equilibration step; GE Healthcare), and consisting in two baths of $20 \mathrm{~min}$ each. The strips were placed at the top of $12 \%$ acrylamide-bisacrylamide gels and maintained in position with $2 \mathrm{ml}$ of stacking gel. The run was performed with a PROTEAN 3 apparatus (Bio-Rad) at a constant power of $8 \mathrm{~W}$ until the Bromophenol Blue (Merck S.A., Lyon, France) reached the bottom of the gels. Gels were washed twice for 5 min and stained with Imperial Blue ${ }^{\circledR}$ (Fisher Scientific, Illkirch-Graffenstaden, France) according to manufacturer's instructions. Three independent experiments were performed in duplicate.

Spot detection and quantification. The 2-D gels were scanned with a GS-800 densitometer (Bio-Rad). Spot detection, quantification and analysis were performed with the SameSpots ${ }^{\circledR}$ v4.1 analysis software (Nonlinear Dynamics, Ltd., Newcastle upon Tyne, UK). Following linearization towards a reference gel chosen among the experimental gels, they were grouped either as control or treated. Each group was the result of three independent experiments performed in duplicate. Spot detection and quantification were determined and a difference was considered to be significant, due to the staining method used, when a 1.5-fold increase or decrease at least was reached. Statistics using ANOVA were given with the in-built statistical software.

In-gel digestion of protein. The protein spots differentially expressed were excised manually and washed five times for 6 min with $100 \mu \mathrm{l}$ water. Then the gel spots were soaked in 
acetonitrile and dried under vacuum. The gel pieces were rehydrated in a reduction buffer [ammonium bicarbonate $100 \mathrm{mM}$ (Sigma-Aldrich), DTT $10 \mathrm{mM}$ (GE Healthcare)] for $1 \mathrm{~h}$ at $56^{\circ} \mathrm{C}$ and $5 \mathrm{~min}$ at room temperature. After removing this buffer, they were incubated with an alkylation buffer (ammonium bicarbonate $100 \mathrm{mM}$, IAM $55 \mathrm{mM}$ ) for $45 \mathrm{~min}$ at room temperature and protected from light. Then, they were washed in a $25-\mathrm{mM}$ ammonium bicarbonate buffer followed by acetonitrile (Merck S.A.) and finally dried under vacuum. The gel pieces were rehydrated in $100 \mu \mathrm{l}$ of $25 \mathrm{mM}$ ammonium bicarbonate and incubated with $125 \mathrm{ng}$ of Trypsin Gold (Mass Spectrometry Grade; Promega France, Charbonnières-les-Bains, France) for $1 \mathrm{~h}$ on ice. The trypsin digestion was performed for $12 \mathrm{~h}$ at $37^{\circ} \mathrm{C}$ after addition of $30 \mu \mathrm{l}$ of $25 \mathrm{mM}$ ammonium bicarbonate.

Mass spectrometry analysis. Mass spectrometry analyses were performed using an Ultraflex ${ }^{\mathrm{TM}}$ II MALDI-TOF/TOF instrument (Bruker Daltonics, Bremen, Germany). MALDI target plate (AnchorChip ${ }^{\mathrm{TM}}$; Bruker Daltonics) was covered with extracted peptides mixed-up with $\alpha$-cyano-4-hydroxycinnamic acid matrix $(0.3 \mathrm{mg} / \mathrm{ml}$ in acetone:ethanol, 3:6 v/v). The molecular mass measurements were obtained as previously described (26). Database searches, through Mascot v.2.2.1 (Matrix Science, Ltd., London, UK), using combined PMF and PFF datasets were performed against the UnitProt 2013-06 database (2013-06-17) via ProteinScape 2.1 (Bruker Daltonics). A mass tolerance of $75 \mathrm{ppm}$ and one missing cleavage site for PMF and MS/MS tolerance of $0.5 \mathrm{Da}$ and one missing cleavage site for MS/MS search were allowed. Carbamidomethylation of cysteine and oxidation of methionine residues were also considered. Relevance of protein identities was judged according to the probability-based MOWSE score calculated with a P-value of $0.05(\mathrm{P} \leq 0.05)$.

Preparation of siRNA and cell transfection. A siRNA (Eurogentec S.A.,Seraing, Belgium) directed against KRT1 was used and defined by (GGA-UGU-GGA-UGG-UGC-UUA-U55) for the forward strand and (AUA-AGC-ACC-AUC-CACAUC-C55) for the reverse. In addition a control siRNA (NEG) provided by the manufacturer was used. The different siRNA were rehydrated with ultrapure water to obtain a concentration of $20 \mu \mathrm{M}$. In a 24 -well plate, $4 \times 10^{5}$ living cells/well were seeded. After $12 \mathrm{~h}$, the medium was removed and rinsed twice with $1 \mathrm{ml} /$ well of Opti-MEM. Then $950 \mu \mathrm{l}$ of Opti-MEM were added with $50 \mu 1$ of a mixture containing Lipofectamine (Invitrogen) with or without the appropriate siRNA. To form the mixture, $2.5 \mu \mathrm{l}$ siRNA at $20 \mu \mathrm{M}$ were mixed with $22.5 \mu \mathrm{l}$ Opti-MEM, and apart, $8.32 \mu \mathrm{l}$ Lipofectamine were homogenized with $16.68 \mu \mathrm{l}$ Opti-MEM. The two solutions were then mixed. After $10 \mathrm{~min}$ of incubation at room temperature the mixture was transferred to culture wells. Incubation was for $4 \mathrm{~h}$ at $37^{\circ} \mathrm{C}$ with $5 \% \mathrm{CO}_{2}$. The medium was discarded and replaced with $1 \mathrm{ml}$ Opti-MEM containing 5\% FCS with or without $100 \mu \mathrm{M}$ DHA. After $24 \mathrm{~h}$, cells were harvested for invasion assay.

Invasion assays and Hoechst staining. Invasion assays were done in 12-well Boyden microchambers (Transwell ${ }^{\circledR}$; Fisher
Scientific) with $8-\mu$ m pore membranes. Matrige ${ }^{\circledR}(100 \mu \mathrm{l}$; BD Biosciences, Le Pont de Claix, France) at 10\% in MEM were introduced in the upper chamber and dried overnight at $37^{\circ} \mathrm{C}$. Cells treated or not for $24 \mathrm{~h}$ as described in the previous section were dissociated with Versene and counted by using a Malassez hemocytometer. Living cells $\left(2 \times 10^{5}\right)$ treated or not in $400 \mu \mathrm{l}$ MEM supplemented with $0.5 \%$ FCS and $1 \%$ BSA were then loaded into the upper chamber. A volume of $800 \mu \mathrm{l}$ of MEM with $0.5 \%$ FCS, and $1 \%$ BSA was introduced into the lower chamber. After incubating for $24 \mathrm{~h}$, the Transwell ${ }^{\circledR}$ was rinsed with PBS, and the Matrige ${ }^{\circledR}$ was scraped off the upper surfaces of the membranes. The cells remaining on the underside of the membrane were fixed for $30 \mathrm{~min}$ at $-20^{\circ} \mathrm{C}$ in methanol, then stained with Hoechst stain (H6024; Sigma-Aldrich), and mounted on glass slides with glycerol for fluorescence microscopy (Merck S.A.) before counting (15 fields/membrane) under a UV microscope (Biomed with fluorescence equipment; Leica, Rueil-Malmaison, France). Light and fluorescent micrographs were taken with the Lasez software (Leica). Three independent experiments were performed in duplicate.

Immunocytochemistry. Experiments were performed with $5 \times 10^{4}$ cells/chamber on a 16 -chamber slide (Fisher Scientific) overnight. Then $200 \mu \mathrm{l}$ of the Lipofectamine mixture with or without siRNA were added for $4 \mathrm{~h}$ after medium withdrawal and rinsing with $500 \mu \mathrm{l}$ Opti-MEM. Then $200 \mu \mathrm{l}$ Opti-MEM containing $5 \%$ SVF with or without $100 \mu \mathrm{M}$ DHA were added for $24 \mathrm{~h}$. Chambers were rinsed with PBS and cells fixed with ethanol-methanol-ultrapure water (1:1:2) for $1 \mathrm{~h}$ at $-20^{\circ} \mathrm{C}$. Cells were treated for endogenous peroxidase with $100 \mu \mathrm{l}$ PBS containing $3 \% \mathrm{H}_{2} \mathrm{O}_{2} 20 \mathrm{vol}$, for $10 \mathrm{~min}$ at room temperature. Then the medium was discarded and $200 \mu \mathrm{l}$ of PBS containing 5\% BSA was added for $1 \mathrm{~h}$ followed by an incubation of $2 \mathrm{~h}$ with $100 \mu \mathrm{l}$ mouse monoclonal anti-KRT1 antibody (Mab 191-05; Diagnostic BioSystems, Inc., Hague, The Netherlands) at 1/500 diluted in PBS with $0.5 \%$ BSA. Cells were rinsed three times with $200 \mu$ PBS $0.5 \%$ BSA. HRP anti-mouse antibody (Sigma-Aldrich) at 1/200 in PBS $0.5 \%$ BSA was added for $1 \mathrm{~h}$. Cells were rinsed three times with PBS $0.5 \%$ BSA and three times with PBS prior HRP revelation by the adjunction of $100 \mu 1$ diaminobenzidine (DAB) prepared in $10 \mathrm{ml}$ water with $20 \mu 1 \mathrm{H}_{2} \mathrm{O}_{2} 20$ vol and counterstained with Hoechst staining. Slides were washed with water and mounted with glycerol for fluorescence microscopy. For each chamber, 10 randomized fields were photographed and analyzed with the Quantity One software (Bio-Rad). Staining intensity in one field was divided by the number of nuclei observed by Hoechst staining in the same field in order to have the average value of KRT1 immunoreactivity. Three independent experiments were performed in duplicate.

Statistics. Statistical analyses for cell culture were performed using KyPlot ${ }^{\circledR}$ (KyensLab, Inc., Tokyo, Japan) for a oneway ANOVA followed by a Dunnett's test to compare untreated or control cells with the treated one. P-value of $<0.01$ and $<0.001$ respectively, indicates statistically significant result. In the figures shown as ${ }^{* *} \mathrm{P}<0.01$ and ${ }^{* * *} \mathrm{P}<0.001$ Statistics for $2-\mathrm{DE}$ are described in the corresponding paragraph. 
Table I. Upregulated proteins in DHA-treated MDA-MB-231 cells. Cells were treated for $24 \mathrm{~h}$ with $100 \mu \mathrm{M}$ DHA before membrane protein preparation, 2-DE and identification in mass spectrometry.

\begin{tabular}{rccccc}
\hline Spot identifier & Fold & Regulation & ANOVA P-value & Protein name & UniProt ID \\
\hline 70 & 2.0 & $\mathrm{Up}$ & 0.017 & KRT1 & P04264 \\
110 & 1.7 & $\mathrm{Up}$ & 0.008 & Catalase & P04040 \\
219 & 1.9 & $\mathrm{Up}$ & 0.022 & Lamin-A/C & P02545 \\
\hline
\end{tabular}

DHA, docosahexaenoic acid; 2-DE, two-dimensional electrophoresis; KRT1, keratin, type II cytoskeletal 1.

Table II. Characteristics of the different peptides for each protein identified in mass spectrometry.

\begin{tabular}{|c|c|c|c|c|c|c|c|}
\hline UniProt ID & $\begin{array}{l}\mathrm{MW} \\
(\mathrm{kDa})\end{array}$ & $\mathrm{pI}$ & $\begin{array}{l}\text { Score } \\
\text { mascot }\end{array}$ & $\begin{array}{c}\text { MS1a }^{\mathrm{a}} \\
\text { coverage }(\%)\end{array}$ & $\begin{array}{c}\text { Peptide } \\
\text { sequence MS2 } 2^{\mathrm{b}}\end{array}$ & $\begin{array}{l}\text { Score } \\
\text { MS2 }^{\text {b }}\end{array}$ & $\begin{array}{c}\text { MS2 }^{\mathrm{b}} \\
\text { coverage (\%) }\end{array}$ \\
\hline P04264 & 65.9 & 8.1 & 65.8 & 31.7 & $\begin{array}{l}\text { WELLQQVDTSTR } \\
\text { THNLEPYFESFINNLR }\end{array}$ & 62.4 & 4.4 \\
\hline P04040 & 59.7 & 6.9 & 110 & 44.8 & $\begin{array}{l}\text { LFAYPDTHR } \\
\text { LGPNYLHIPVNCPYR } \\
\text { AFYVNVLNEEQR }\end{array}$ & 116.4 & 6.8 \\
\hline P02545 & 74.1 & 6.6 & 107 & 37.5 & $\begin{array}{l}\text { LQEKEDLQELNDR } \\
\text { NSNLVGAAHEELQQSR }\end{array}$ & 62 & 4.4 \\
\hline
\end{tabular}

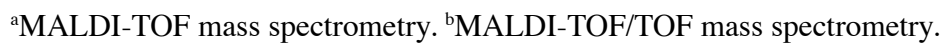

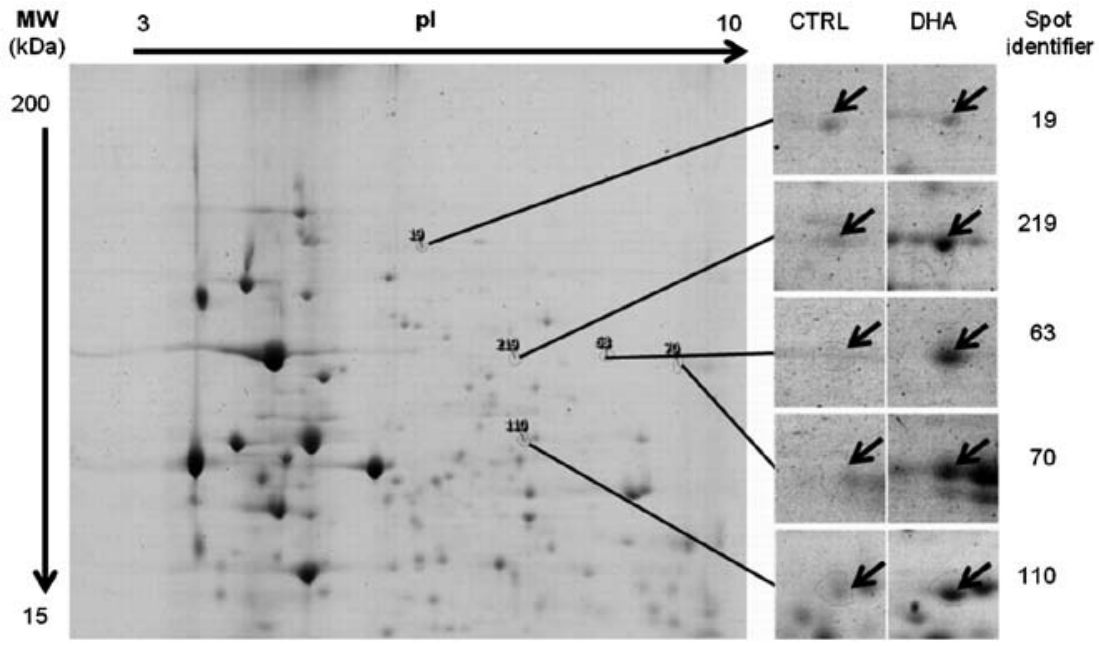

Figure 1. Docosahexaenoic acid (DHA)-treated MDA-MB-231 cells induced a differential membrane protein expression. Two-dimensional electrophoresis (2-DE) was performed with membrane proteins of MDA-MB-231 cells treated or not for $24 \mathrm{~h}$ with $100 \mu \mathrm{M}$ DHA, using $7 \mathrm{~cm}$ isoelectric focusing (IEF) strips pH $3.0-10.0$ and 12\% SDS-PAGE. The left panel shows the location of the different spots on the gel of MDA-MB-231 membrane proteins. The right panel shows the details of five spots having at least a 1.5-fold down- or upregulation between control and DHA-treatment. Results correspond to the compilation of three independent experiments performed in duplicate. Other spots were still statistically different but were not taken into consideration because their respective regulation fold was $<1.5$.

\section{Results}

Identification of differentially expressed proteins in DHA-treated cells. MDA-MB-231 cells treated or not with $100 \mu \mathrm{M}$ DHA for $24 \mathrm{~h}$ were processed to obtain membrane extracts. After 2-DE of membrane proteins (from both DHA-treated and control cells), it appears that only a few membrane proteins displayed at least a 1.5 -fold differential expression pattern (Fig. 1). Four proteins were found upregulated by DHA treatment compared to the control, and one protein was downregulated (Table I). Mass spectrometry for spot no. 19 was not possible due to insufficient protein quantity and for spot no. 63 it was a mixture of proteins. Spots nos. 70, 110 and 219 were identified (Fig. 2; Table II) by microsequencing using coupled 

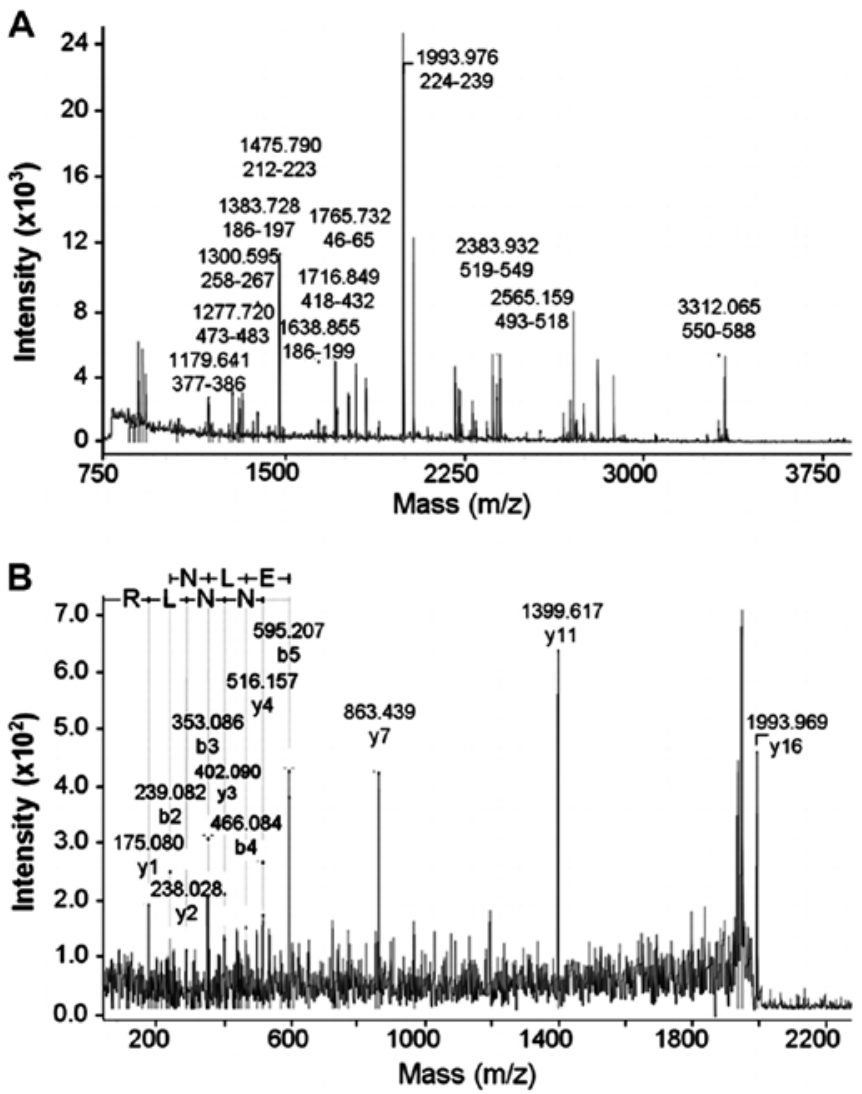

C

MSRQFSSRSG YRSGGGFSSG SAGIINYQRR TTSSSTRRSG GGGGRFSSCG $\quad 50$ GGGGSFGAGG GFGSRSLVNL GGSKSISISV ARGGGRGSGF GGGYGGGGFG $\quad 100$ GGGFGGGGFG GGGIGGGGFG GFGSGGGGFG GGGFGGGGYG GGYGPVCPPG 150 GIQEVTINQS LLOPLNVEID PEIQKVKSRE REQIKSLNNQ FASFIDKVRF 200 LEQQNQVLQT KWELLQQVDT STRTHNLEPY FESFINNLRR RVDQLKSDQS 250 RLDSELKNMQ DMVEDYRNKY EDEINKRTNA ENEFVTIKKD VDGAYMTKVD 300 LQAKLONLQQ EIDFLTALYQ AELSQMQTQI SETNVILSMD NNRSLDLDSI 350 IAEVKAQYED IAQKSKAEAE SLYQSKYEEL QITAGRHGDS VRNSKIEISE $\quad 400$ LNRVIQRLRS EIDNYKKOIS NLCOSISDAE QRGENALKDA KNKLNDLEDA 450 LQQAKEDLAR LLRDYQELMN TKLALDLEIA TYRTLLEGEE SRMSGECAPN 500 VSVSVSTSHT TISGGGSRGG GGGGYGSGGS SYGSGGGSYG SGGGGGGGRG 550 SYGSGGSSYG SGGGSYGSGG GGGGHGSYGS GSSSGGYRGG SGGGGGGSSG 600 GRGSGGGSSG GSIGGRGSSS GGVKSSGGSS SVKFVSTTYS GVTR 644

Figure 2. MALDI-TOF and MS-MS spectra corresponding to keratin, type II cytoskeletal 1 (KRT1). (A) MALDI-TOF and (B) an example of MS-MS spectra obtained for spot no. 70 (Fig. 1). The spot was excised from the gel and trypsin-digested. After MALDI-TOF and database searching, 12 peptides matched with theoretical masses, leading to a sequence coverage of $31.7 \%$. This identification of KRT1 was confirmed by the sequencing of two peptides in MS-MS. (C) The amino acid sequences underlined with a thin grey line correspond to the 12 peptides obtained in MS and the sequences underlined twice with a thin grey line and a thick dark line correspond to the two sequences obtained in MS-MS.

mass spectrometry as being KRT1 (UniProt ID P04264), catalase (UniProt ID P04040) and lamin-A/C (UniProt ID P02545), respectively.

DHA-induced KRT1 protein upregulation and inhibition by siRNA. The increase of KRT1 in DHA-treated cells was confirmed by immunocytochemistry (Fig. 3). KRT1 was present in the cytoplasm of untreated (Fig. 3A) and

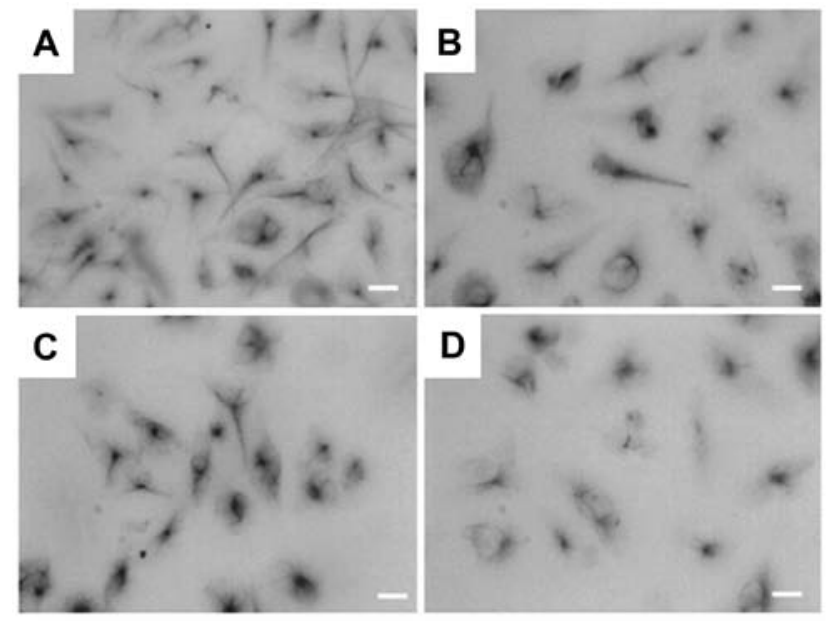

E

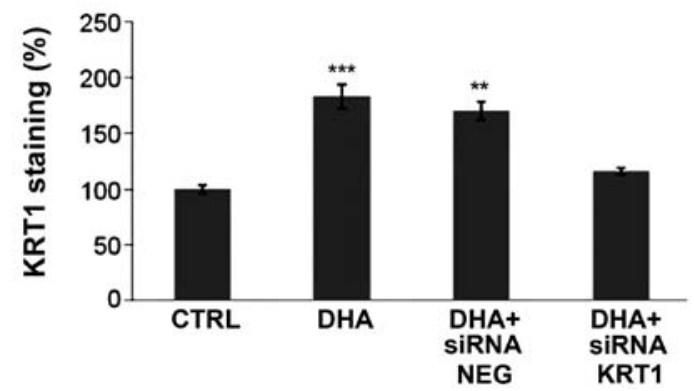

Figure 3. Keratin, type II cytoskeletal 1 (KRT1) detection and expression in MDA-MB-231 cells. The microphotographs show the presence of KRT1 in (A) untreated control cells and (B-D) docosahexaenoic acid (DHA)-treated cells. (C) Negative control siRNA and (D) KRT1-directed siRNA were added at a concentration of $50 \mathrm{nM}$ and Lipofectamine was added to all conditions as detailed in Materials and methods section. Cells were incubated with mouse monoclonal anti-KRT1 antibodies and anti-mouse HRP secondary antibody and stained using diaminobenzidine (DAB). A counterstain of nuclei was made with Hoechst staining. (E) Bars correspond to $25 \mu \mathrm{m}$. KRT1 expression in DHA-treated cells is inhibited by siRNA against KRT1. After immunocytochemistry, micrograph was performed by using a light microscope with a 40x objective lens for KRT1 location. Micrograph of the same field was also done with a fluorescence microscope to obtain the number of nuclei. The quantification of KRT1 among the different treatments was obtained for a given field after micrograph by calculation of the density within the field minus the background obtained by the density present on a slide without cells and then divided by the number of cells present in the field. Results are the mean \pm SD of three independent experiments. Statistics were obtained by using KyPlot ${ }^{\circledast}$ software with a Dunnett's test and comparison with the control. ${ }^{* *} \mathrm{P} \leq 0.01$ and ${ }^{* * *} \mathrm{P} \leq 0.001$.

treated (Fig. 3B-D) cells. KRT1 labeling was quantified by using Quantity One software (Bio-Rad). The result was then subtracted by the blank of a similar surface without cells and divided by the number of nucleus present in the field. Thus, the average KRT1 quantification corresponded to a single cell expressed as a percentage (Fig. 3E). The result indicated that control siRNA (NEG) had no effect on the level of KRT1 in the DHA-treated cells and in the control. In the cells treated with DHA and siRNA against KRT1, we observed a level of KRT1 that was reduced nearly to what was observed in the control (Fig. 3E).

DHA-induced decrease of breast cancer cell invasiveness is reversed by siRNA against KRT1. Using Matrigel ${ }^{\circledR}$ in Boyden chambers, DHA was shown to reduce the invasive potential of MDA-MB-231 cells (Fig. 4). In order to investigate the role of 


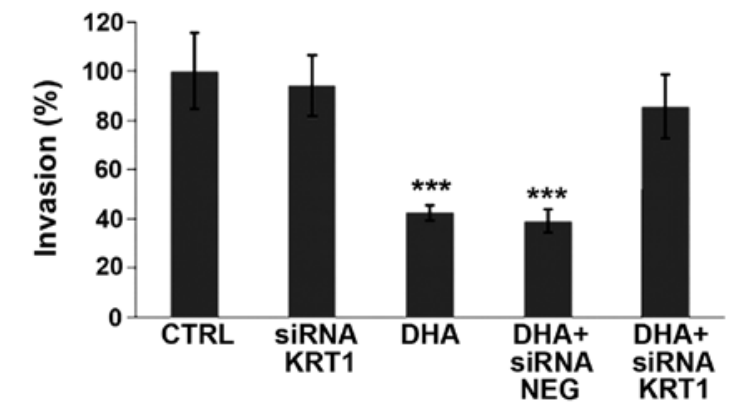

Figure 4. Docosahexaenoic acid (DHA)-induced decrease of the invasive potential of MDA-MB-231 cells is reversed by keratin, type II cytoskeletal 1 (KRT1) siRNA. The invasive potential of control and DHA-treated cells was assayed using Matrige ${ }^{\circledR}$ in Boyden chambers. Control siRNA (NEG) and siRNA directed against KRT1 were added at a concentration of $50 \mathrm{nM}$ to DHA-treated cells and non-treated cells. Results are the mean \pm SD of three independent experiments performed in duplicate. Statistics were obtained by using KyPlot ${ }^{\circledast}$ software with a Dunnett's test and comparison with the control. ${ }^{* * * *} \mathrm{P} \leq 0.001$.

the differentially expressed KRT1 protein, siRNAs were used in the invasion assay in presence or absence of DHA. siRNA against KRT1 was able to restore a percentage of invasive cells similar to the control level while the control siRNA NEG was inefficient (Fig. 4). This indicated the involvement of KRT1 in the DHA-induced decrease of MBA-MB-231 cell invasiveness.

\section{Discussion}

The pro-apoptotic effect of DHA on cancer cells and especially in breast cancer is well known (11). However, few studies have also shown the inhibitory effect of DHA on the metastatic and invasive potential of cancer cells $(9,27,28)$. In order to identify membrane proteins from MDA-MB-231 that could be involved, a 2-DE-based proteomic analysis was performed with crude membrane preparations. This allowed the identification of three differentially expressed proteins after DHA treatment. Besides, it appeared that these proteins are well expressed in differentiated cells and it is possible that the effects observed could be due to the DHA effect on cell differentiation as reported by Siddiqui et al (29). Interestingly, lamin-A/C, a protein of the nuclear envelope, was present and upregulated in the crude membrane extract from DHA-treated cells. In stage II and III colon cancer patients, low expression of lamin-A/C was associated with an increased disease recurrence (30). In breast cancer, it has been shown that higher lamin-A/C expression is associated with: i) early clinical stage; ii) a better clinical outcomes; and iii) a better overall and disease-free survival, suggesting a significant role for nuclear and chromosomal stability in this pathology (31). Therefore, an increased in lamin-A/C expression appears to be related to a less aggressive phenotype of breast cancer cells, and our results are well in range with this notion by showing that the inhibition of MDA-MB-231 invasiveness induced by DHA is accompanied by an increase in lamin-A/C.

The enzyme catalase was also upregulated after DHA treatment, which is in agreement with its protective role against reactive oxygen species (ROS) and the induction of apoptosis by DHA $(32,33)$. Moreover, ROS can induce cell migration and invasion $(34,35)$, and their impact is well established in the migration process triggered by growth factors able to activate tyrosine kinase receptors and MAPK (36). It has been shown that the lysyl oxidase (LOX) facilitates the invasion of MDA-MB-231 cells and that the removal of hydrogen peroxide leads to a dose-dependent loss in Src activation (37). Consequently, LOX was shown to facilitate migration and cell-matrix adhesion in invasive breast cancer cells through a hydrogen peroxide-mediated mechanism involving the FAK/Src signaling pathway (37). It has been shown that an increase in catalase results in a decreased ROS level close to the plasma membrane and leads to a reduction of migration and invasion (38). Consequently, the increased level of catalase observed in MDA-MB-231 crude membranes is well in range with other studies and is related to a decreased invasiveness.

Our study reports that KRT1 is induced upon stimulation of cancer cells by DHA. siRNA against KRT1 was able to reduce the de novo expression of KRT1 induced by DHA treatment in MDA-MB-231 cells, then leading to the reacquisition of an invasive potential. It has been shown that DHA is able to selectively alter the subcellular distribution of lipidated cytosolic proteins, including Ras isoforms, by modifying membrane lipid composition (39), indicating that KRT1 can be associated with membrane proteins. In addition, KRT1 was shown to interact with the tyrosine kinase Src through binding to integrin $\beta 1$ (23) and therefore the presence of KRT1 in a crude membrane preparation is not surprising. It has been shown that KRT1 level is strongly decreased in breast cancer cells reaching a metastatic phenotype (40). In addition, a recent study has shown that KRT1 is decreased in breast tumors (41). In the same study, KRT1 was also found to be released in sera concomitantly with a $130 \mathrm{kDa}$ epithelial membrane antigen (EMA) and the EMA/CK1 ratio was correlated with more aggressive tumor types. Therefore, KRT1 expression is associated with a less aggressive phenotype of breast cancer and our results suggest a mechanism involving the inhibition of cancer cell invasiveness.

An indirect interaction between KRT1 and Src was previously reported (23) as well as the interaction between Src and the membrane protein $\mathrm{Na}_{\mathrm{v}} 1.5$, a sodium ion channel protein encoded by the SCN5A in humans $(24,42)$. Inactivation of $\mathrm{Na}_{\mathrm{v}} 1.5$ is known to induce a loss of invasion capacity in triple-negative highly metastatic breast cancer cells $(18,43)$. Then it is conceivable that the overexpression of KRT1 observed following DHA treatment may lead to KRT1 interaction with Src and then to $\mathrm{Na}_{\mathrm{v}} 1.5$, but further experiments are needed to elucidate this hypothesis and define the precise mechanisms linking KRT1 and tumor cell invasion.

In conclusion, this proteomics-based study provides new mechanistic insights into the activity of DHA in breast cancer cells and in particular identifies KRT1 upregulation as being involved in the DHA-induced inhibition of breast cancer cell invasion.

\section{Acknowledgements}

We thank Dr S. Duban-Deweer for mass spectrometry analyses (Centre d'Analyse Protéomique de l'Artois). The mass spectrometry facility used for this study was funded by the European Union (FEDER), the Fonds d'Industrialisation du Bassin Minier (FIBM), the Ministère de l'Enseignement Supérieur et de la 
Recherche and l'Université d'Artois. This study was supported by a Grant from the Mayenne Council.

\section{References}

1. Larsson SC, Kumlin M, Ingelman-Sundberg M and Wolk A Dietary long-chain n-3 fatty acids for the prevention of cancer: A review of potential mechanisms. Am J Clin Nutr 79: 935-945, 2004.

2. Doughman SD, Krupanidhi S and Sanjeevi CB: Omega-3 fatty acids for nutrition and medicine: Considering microalgae oil as a vegetarian source of EPA and DHA. Curr Diabetes Rev 3: 198-203, 2007.

3. Poudyal H, Panchal SK, Diwan V and Brown L: Omega-3 fatty acids and metabolic syndrome: Effects and emerging mechanisms of action. Prog Lipid Res 50: 372-387, 2011.

4. Holub BJ: Docosahexaenoic acid (DHA) and cardiovascular disease risk factors. Prostaglandins Leukot Essent Fatty Acids 81: 199-204, 2009.

5. Berquin IM, Edwards IJ and Chen YQ: Multi-targeted therapy of cancer by omega-3 fatty acids. Cancer Lett 269: 363-377, 2008.

6. Bougnoux P, Hajjaji N, Maheo K, Couet C and Chevalier S: Fatty acids and breast cancer: Sensitization to treatments and prevention of metastatic re-growth. Prog Lipid Res 49: 76-86, 2010.

7. Holmes MD and Willett WC: Does diet affect breast cancer risk? Breast Cancer Res 6: 170-178, 2004.

8. Barascu A, Besson P, Le Floch O, Bougnoux P and Jourdan ML: CDK1-cyclin B1 mediates the inhibition of proliferation induced by omega-3 fatty acids in MDA-MB-231 breast cancer cells. Int J Biochem Cell Biol 38: 196-208, 2006.

9. Blanckaert V, Ulmann L, Mimouni V, Antol J, Brancquart L and Chénais B: Docosahexaenoic acid intake decreases proliferation, increases apoptosis and decreases the invasive potential of the human breast carcinoma cell line MDA-MB-231. Int J Oncol 36: 737-742, 2010

10. Stoll BA: Breast cancer and the western diet: Role of fatty acids and antioxidant vitamins. Eur J Cancer 34: 1852-1856, 1998.

11. Chénais B and Blanckaert V: The janus face of lipids in human breast cancer: How polyunsaturated fatty acids affect tumor cell hallmarks. Int J Breast Cancer 2012: 712536, 2012.

12. Stillwell W and Wassall SR: Docosahexaenoic acid: Membrane properties of a unique fatty acid. Chem Phys Lipids 126: 1-27, 2003.

13. Conn EM, Botkjaer KA, Kupriyanova TA, Andreasen PA, Deryugina EI and Quigley JP: Comparative analysis of metastasis variants derived from human prostate carcinoma cells: Roles in intravasation of VEGF-mediated angiogenesis and uPA-mediated invasion. Am J Pathol 175: 1638-1652, 2009.

14. Brooks SA, Lomax-Browne HJ, Carter TM, Kinch CE and Hall DM: Molecular interactions in cancer cell metastasis. Acta Histochem 112: 3-25, 2010.

15. Buxton IL, Yokdang N and Matz RM: Purinergic mechanisms in breast cancer support intravasation, extravasation and angiogenesis. Cancer Lett 291: 131-141, 2010.

16. Schley PD, Brindley DN and Field CJ: (n-3) PUFA alter raft lipid composition and decrease epidermal growth factor receptor levels in lipid rafts of human breast cancer cells. J Nutr 137: 548-553, 2007.

17. Raghu H, Sodadasu PK, Malla RR, Gondi CS, Estes N and Rao JS: Localization of UPAR and MMP-9 in lipid rafts is critical for migration, invasion and angiogenesis in human breast cancer cells. BMC Cancer 10: 647-664, 2010.

18. Isbilen B, Fraser SP and Djamgoz MB: Docosahexaenoic acid (omega-3) blocks voltage-gated sodium channel activity and migration of MDA-MB-231 human breast cancer cells. Int J Biochem Cell Biol 38: 2173-2182, 2006.

19. Gillet L, Roger S, Bougnoux P, Le Guennec JY and Besson P: Beneficial effects of omega-3 long-chain fatty acids in breast cancer and cardiovascular diseases: Voltage-gated sodium channels as a common feature? Biochimie 93: 4-6, 2011.

20. Maguy A, Hebert TE and Nattel S: Involvement of lipid rafts and caveolae in cardiac ion channel function. Cardiovasc Res 69 798-807, 2006

21. Sánchez-Bailón MP,Calcabrini A,Gómez-DomínguezD,Morte B, Martín-Forero E, Gómez-López G, Molinari A, Wagner KU and Martín-Pérez J: Src kinases catalytic activity regulates proliferation, migration and invasiveness of MDA-MB-231 breast cancer cells. Cell Signal 24: 1276-1286, 2012.
22. Planas-Silva MD, Bruggeman RD, Grenko RT and Smith JS: Role of c-Src and focal adhesion kinase in progression and metastasis of estrogen receptor-positive breast cancer. Biochem Biophys Res Commun 341: 73-81, 2006.

23. Chuang NN and Huang CC: Interaction of integrin betal with cytokeratin 1 in neuroblastoma NMB7 cells. Biochem Soc Trans 35: 1292-1294, 2007.

24. Andavan B, Shankar G and Lemmens-Gruber R: Modulation of $\mathrm{Na}_{\mathrm{v}} 1.5$ variants by src tyrosine kinase. Biophys J 98: 310a, 2010.

25. Venkateswaran S, Blanckaert V and Schelling M: Membrane fragments from cultured endothelial cells for use in screening anti-FGF receptor antibodies. Methods Cell Sci 14: 159-162, 1992.

26. Wilmet JP, Tastet C, Desruelles E, Ziental-Gelus N, Blanckaert V, Hondermarck $\mathrm{H}$ and Le Bourhis X: Proteome changes induced by overexpression of the p75 neurotrophin receptor (p75NTR) in breast cancer cells. Int J Dev Biol 55: 801-809, 2011.

27. D'Eliseo D, Manzi L, Merendino N and Velotti F: Docosahexaenoic acid inhibits invasion of human RT112 urinary bladder and PT45 pancreatic carcinoma cells via down-modulation of granzyme B expression. J Nutr Biochem 23: 452-457, 2012.

28. Mandal CC, Ghosh-Choudhury T, Yoneda T, Choudhury GG and Ghosh-Choudhury N: Fish oil prevents breast cancer cell metastasis to bone. Biochem Biophys Res Commun 402: 602-607, 2010.

29. Siddiqui RA, Harvey KA, Walker C, Altenburg J, Xu Z, Terry C, Camarillo I, Jones-Hall Y and Mariash C: Characterization of synergistic anti-cancer effects of docosahexaenoic acid and curcumin on DMBA-induced mammary tumorigenesis in mice. BMC Cancer 13: 418-434, 2013.

30. Belt EJ, Fijneman RJ, van den Berg EG, Bril H, Delis-van Diemen PM, Tijssen M, van Essen HF, De Lange-de Klerk ES, Beliën JA, Stockmann HB, et al: Loss of lamin A/C expression in stage II and III colon cancer is associated with disease recurrence. Eur J Cancer 47: 1837-1845, 2011.

31. Wazir U, Ahmed MH, Bridger JM, Harvey A, Jiang WG, Sharma AK and Mokbel K: The clinicopathological significance of lamin $\mathrm{A} / \mathrm{C}$, lamin B1 and lamin B receptor mRNA expression in human breast cancer. Cell Mol Biol Lett 18: 595-611, 2013.

32. Yu L, Wan F, Dutta S, Welsh S, Liu Z, Freundt E, Baehrecke EH and Lenardo M: Autophagic programmed cell death by selective catalase degradation. Proc Natl Acad Sci USA 103: 4952-4957, 2006.

33. Bechtel W and Bauer G: Catalase protects tumor cells from apoptosis induction by intercellular ROS signaling. Anticancer Res 29: 4541-4557, 2009.

34. Richard D, Hollender P and Chénais B: Butyric acid increases invasiveness of HL-60 leukemia cells: Role of reactive oxygen species. FEBS Lett 518: 159-163, 2002.

35. Richard D, Hollender P and Chénais B: Involvement of reactive oxygen species in aclarubicin-induced differentiation and invasiveness of HL-60 leukemia cells. Int J Oncol 21: 393-399, 2002

36. Hurd TR, DeGennaro M and Lehmann R: Redox regulation of cell migration and adhesion. Trends Cell Biol 22: 107-115, 2012.

37. Payne SL, Fogelgren B, Hess AR, Seftor EA, Wiley EL, Fong SF, Csiszar K, Hendrix MJ and Kirschmann DA: Lysyl oxidase regulates breast cancer cell migration and adhesion through a hydrogen peroxide-mediated mechanism. Cancer Res 65 : 11429-11436, 2005.

38. Nikitovic D, Corsini E, Kouretas D, Tsatsakis A and Tzanakakis G: ROS-major mediators of extracellular matrix remodeling during tumor progression. Food Chem Toxicol 61: 178-186, 2013.

39. Seo J, Barhoumi R, Johnson AE, Lupton JR and Chapkin RS: Docosahexaenoic acid selectively inhibits plasma membrane targeting of lipidated proteins. FASEB J 20: 770-772, 2006.

40. DeAngelis JT,Li Y,Mitchell N, Wilson L, Kim H and Tollefsbol TO: 2D difference gel electrophoresis analysis of different time points during the course of neoplastic transformation of human mammary epithelial cells. J Proteome Res 10: 447-458, 2011.

41. Attallah AM,El-FarM, Omran MM,Abdallah SO,El-Desouky MA, El-Dosoky I, Abdelrazek MA, Attallah AA, Elweresh MA, Abdel Hameed GE, et al: Circulating levels and clinical implications of epithelial membrane antigen and cytokeratin-1 in women with breast cancer: Can their ratio improve the results? Tumour Biol 35: 10737-10745, 2014

42. Rohl CA, Boeckman FA, Baker C, Scheuer T, Catterall WA and Klevit RE: Solution structure of the sodium channel inactivation gate. Biochemistry 38: 855-861, 1999.

43. Yang M, Kozminski DJ, Wold LA, Modak R, Calhoun JD, Isom LL and Brackenbury WJ: Therapeutic potential for phenytoin: Targeting $\mathrm{Na}(\mathrm{v}) 1.5$ sodium channels to reduce migration and invasion in metastatic breast cancer. Breast Cancer Res Treat 134 603-615, 2012. 